ELECTROMECHANICAL ANALYSIS OF THE TECHNOLOGY DEMONSTRATOR FOR THE IGNITEX FUSION DEVICE

M. D. Driga, K. T. Hsieh, W. F. Weldon, and M. D. Werst

Presented at the Eighth Topical Meeting on the Technology of Fusion Energy

Salt Lake City, Utah

October 9-13, 1988

Publication No. PR-92

Center for Electromechanics

The University of Texas at Austin

Balcones Research Center

EME 1.100, Building 133

Austin, TX 78758-4497

(512) $471-4496$ 


\title{
ELECTROMECHANICAL ANALYSIS OF THE TECHNOLOGY DEMONSTRATOR FOR THE IGNITEX FUSION DEVICE
}

\author{
M. D. Driga, K. T. Hsieh, W. F. Weldon, and M. D. Werst \\ Center for Electromechanics at The University of Texas at Austin \\ 10100 Burnet Road, Bldg. 133 \\ Austin, TX 78758-4497 \\ (512) $471-4496$
}

\section{ABSTRACT}

The Texas Ignition Experiment (IGNITEX) device is a single turn coil tokamak designed to produce and control an ignited plasma using ohmic heating alone. The proposed high strength magnet system operates at a magnetic field on-axis of $20 \mathrm{~T}$, using homopolar generators (HPGs), which meet the power supply requirements (150 MA, $10 \mathrm{~V})$ inexpensively.

In this paper, the electromechanical analysis of a scaled down prototype (1/10 scale in linear dimensions) of the IGNITEX toroidal field (TF) magnet is presented. The primary goal of the IGNITEX Technology Demonstrator (ITD) is to prove the operation of a single turn, $20 \mathrm{~T}$, toroidal field coil powered by a homopolar generator power supply system of $60 \mathrm{MJ}, 9 \mathrm{MA}$, currently operating at the Center for Electromechanics, The University of Texas at Austin (CEM-UT).

In order to simulate the actual operating conditions of the full-scale device, the ITD coil will be precooled at liquid nitrogen temperature and driven by the six homopolar generators in parallel .

Scaling relationships have shown that electromagnetic loading mechanical and thermal loading of the coil and their relative distribution will approximate well predicted levels of the full-scale IGNITEX device.

\section{INTRODUCTION}

One of the most immediate prospects to produce a fusion ignited plasma is the IGNITEX experiment, proposed in 1 as a compact, high field tokamak device $(r \approx 1.5 \mathrm{~m}, \mathrm{~B} \approx 20 \mathrm{~T})$ in which the controlled $D-T$ fusion can be obtained by ohmic heating alone 2 .

Such a device could provide ignition with a substantial cost savings making it a very attractive alternative when compared with other immediate prospects, especially when the shorter time-scale involved in such an experiment and the uncertainties in understanding and predictive capabilities of the present plasma physics are considered. IGNITEX has a single-turn configuration for the toroidal field coil, adopted to maximize load-carrying ability and virtually eliminate electrical insulation limitations. The power supply requirements, in order to produce a $20 \mathrm{~T}$ onaxis field, are high current (150 MA) and low voltage $(10 \mathrm{~V})$, that can be satisfied inexpensively by the use of HPGs using unique technologies developed at The University of Texas at Austin over the last 15 years.

In order to demonstrate the ability of the technology to build and operate the IGNITEX experiment, an ITD has been proposed and funded under the Texas Advanced Technology Program. The ITD will be built as a 1/10 scale prototype of the full-scale ignition device. It is intended to prove the operation of a $20 \mathrm{~T}$ on-axis toroidal magnetic field, which is substantially higher than the field generated in conventional toroidal fusion experiments so far. The concept depends upon a unique combination of toroidal magnet geometry, special materials and HPGs as the power supply.

Building and testing the ITD will confirm the ability of the proposed technology to generate and maintain the high toroidal magnetic field in the necessary geometry, reducing substantially the risk of proceeding with the full-scale fusion ignition experiment.

\section{DESCRIPTION OF TF COIL FOR IGNITEX}

The general design philosophy of the magnet system is based on simplicity and robustness. The goal of a 20 T TF is accomplished with a single turn, highly preloaded copper alloy coil, driven by 12 pulsed HPGs to a peak current of $150 \mathrm{MA}$. A singleturn configuration will be built to eliminate the turnto-turn insulation, thus greatly increasing the current-carrying capability of the design. For 
fabrication and power supply purposes, the coil is divided into 12 pie-shaped sections that are galvanically independent from each other (fig. 1). Each sector carries 12.5 MA at peak excitation to achieve the $150 \mathrm{MA}$ total current requirement: The IGNITEX TF coil is precooled to liquid nitrogen temperature before each discharge to lower coil resistive losses and to extend the allowable temperature excursion per shot ${ }^{3}$.
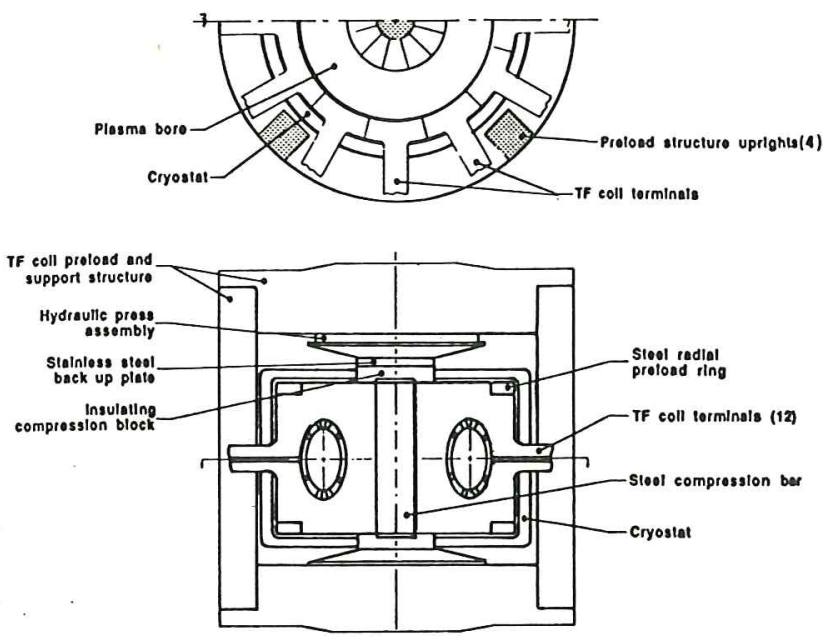

Figure 1. Toroidal field coil system

Material for the single turn coil conductor requires the best combination of yield strength and electrical conductivity at both liquid nitrogen temperature for the beginning of each discharge and above room temperature for the latter stages of a full-current discharge. Of available copper alloys, aluminum oxide dispersion strengthened copper represents an attractive combination of these properties and has been chosen for the baseline design. The material selected for the IGNITEX magnet system is fabricated by SCM Metal Products of Cleveland, Ohio. This material has been in use at CEM-UT for a number of years. The specific material selected is Glidcop Al-15 (CDA 15715), which contains $0.15 \%$ of $\mathrm{Al}_{2} \mathrm{O}_{3}$. This material has a $0.2 \%$ yield strength of $579 \mathrm{MPa}(84 \mathrm{ksi}$ ) and a tensile strength of $606 \mathrm{MPa}$ (88 ksi) with $96 \%$ cold work. The electrical conductivity at room temperature is $92 \%$ IACS, and it increases by a factor of 4.6 at liquid nitrogen temperature. Other properties are given in table 1. Manufacturing of the material starts with molten copper and aluminum. The mixture is made into powder by atomization and then subjected to internal oxidation. The oxygen is preferentially absorbed by the aluminum, and the $\mathrm{Al}_{2} \mathrm{O}_{3}$ remains evenly distributed in the material. The product is reduced and consolidated by hot isostatic pressing, an extrusion process, and then
Table 1. Physical properties of $\mathrm{Al}_{2} \mathrm{O}_{3}$ dispersion strengthened copper

\begin{tabular}{|l|l|l|c|}
\hline PROPERTY & VALUE & UNITS & $\%$ IACS \\
\hline Density & 8,810 & $\mathrm{~kg} / \mathrm{m}^{3}$ & $\ldots$ \\
Thermal expansion & $1.09 \times 10.5$ & in./in. $\cdot{ }^{\circ} \mathrm{F}$ & $\ldots$. \\
Resistivity at $20^{\circ} \mathrm{C}$ & 1.88 & $\mu \Omega \cdot \mathrm{cm}$ & 92 \\
Resistivity at $-196^{\circ} \mathrm{C}$ & 0.41 & $\mu \Omega \cdot \mathrm{cm}$ & 423 \\
Thermal conductivity & 365 & $\mathrm{~W} / \mathrm{m} \cdot \mathrm{K}$ & $\ldots$ \\
Heat capacity & 385 & $\mathrm{~J} / \mathrm{kg} \cdot \mathrm{K}$ & $\ldots$ \\
Yield strength & $580(84)$ & $\mathrm{MPa}(\mathrm{ksi})$ & $\ldots$ \\
Young's modulus & $117(17)$ & $\mathrm{GPa}(\mathrm{Msi})$ & $\ldots$ \\
Fatigue limit & $207(30)$ & $\mathrm{MPa}(\mathrm{ksi})$ & $\ldots$ \\
& & & \\
\hline
\end{tabular}

cold rolling and forming take place. This material has the ability to maintain strength at higher temperatures than most other copper alloys.

Stresses in the single-turn coil are controlled by externally supporting the structure in three ways. First, a $0.8-\mathrm{m}$ diameter steel compression bar is located in the center of the coil to limit inward deflections. Unlike existing experimental tokamak devices, this approach is possible because a central ohmic heating coil is not used. Selection of the 0.8$\mathrm{m}$ diameter for the bar was the result of a tradeoff between coil support and excessive heating in the coil inner leg. To limit peak tensile stress, the coil inner leg is initially preloaded at a compressive stress of $469 \mathrm{MPa}$ (68 ksi), which is applied in a radial zone just around the compression bar and with external radius of $77 \mathrm{~cm}$. This loading allows a very wide stress and deflection excursion without exceeding the material tensile yield during the discharge. A preload force of $638 \mathrm{MN}(65,000$ tons) is applied hydraulically at the top and bottom of the TF coil through insulating compression spacers by an external frame, which also serves to support the weight of the device. Finally, a radial preload of 234 $\mathrm{MPa}$ (34 ksi), applied at the top and bottom of the coil, limits outward radial deflection and works in conjunction with the steel compression bar to restrain bending of the inner coil leg. This radial force is applied by a removable interference fit steel ring which also holds the 12 coil sectors in place against the central compression bar.

The coil is placed in a closed cryostat for pool cooling with liquid nitrogen. Included inside the cryostat are the steel compression bar and the two radial compression rings. The axial preload frame is isolated from the coil by glass/epoxy compression spacers. Since each coil sector is powered by a dedicated HPG, there are 12 sets of terminals which represent the major heat leaks from the cryostat.

The electromechanical analysis for the full-scale TF system has been performed using two- and three-dimensional (2-D and 3-D) finite element electromagnetic and stress codes, under the 
assumptions of an axial preload of $469 \mathrm{MPa}(68 \mathrm{ksi})$ on the coil inner leg, a radial preload of $234 \mathrm{MPa}$ (34 ksi) applied to the top and bottom of the coil as shown in figure 1, and a 150 MA square current pulse shape with a $3 \mathrm{~s}$ linear rise and more than $5 \mathrm{~s}$ flat top. The peak von Mises' stress in the coil material reaches $538 \mathrm{MPa}$ (78 ksi), or about $93 \%$ of the yield point. Since the fatigue limit for this material is about $30 \mathrm{ksi}$, from a fatigue standpoint, the coil structure should be capable of at least 1,000 full current discharges. At $3 / 4$ current (about 15 T), which may be sufficient to reach ignition, it is estimated that the coil can withstand 100,000 discharges. Maximum temperature in the coil after a full current discharge occurs in the inner leg, on the plasma bore, and is very manageable at $145^{\circ} \mathrm{C}$. The current density profile in the "throat" region is initially skewed toward the plasma bore as expected, but as the current diffuses into the coil and material near the plasma bore is resistively heated, the profile becomes more evenly distributed. Average current density in the throat region is about $57 \mathrm{MA} / \mathrm{m}^{2}$, a fairly low value considering the magnitude of the field being generated.

\section{IGNITEX TECHNOLOGY DEMONSTRATOR (ITD)}

As already mentioned, ITD will be built in order to validate the technology to generate and to maintain a $20 \mathrm{~T}$ toroidal magnetic field in the necessary geometry required to produce fusion by ohmic heating alone.

Scaling relationships have lead to an ITD with a scale ratio of $1 / 10$ of the IGNITEX TF coils. Table 2 compares the critical parameters of the full-scale TF coil system and the $1 / 10$ scale technology demonstration. The value of the scale factor was imposed by the available power supply.

Table 2. Comparison of IGNITEX TF magnet system and proposed technology demonstrator

\begin{tabular}{|c|c|c|c|c|}
\hline \multirow[b]{2}{*}{$\begin{array}{l}\text { Major Radius } \\
\text { Minor Radius } \\
\text { Pulse Time } \\
\text { Current } \\
\text { Current Density (inner leg) } \\
\text { Peak Temperature } \\
\text { Maximum Stress (von Mises) } \\
\text { No. of Sectors } \\
\text { Material }\end{array}$} & \multicolumn{2}{|c|}{$\begin{array}{l}\text { IGNITEX } \\
\text { TF Magnot }\end{array}$} & \multicolumn{2}{|c|}{$\begin{array}{c}\text { IGNITEX } \\
\text { Technology (ITD) } \\
\text { Demonstrator }\end{array}$} \\
\hline & $\begin{array}{c}1.5 \\
0.5 \\
10 \\
150 \\
5.7 \\
145.0 \\
540 \\
12 \\
\mathrm{Al}_{2} \mathrm{O}_{3}\end{array}$ & $\begin{array}{l}\mathrm{m} \\
\mathrm{m} \\
8 \\
\mathrm{MA} \\
\mathrm{kA} \mathrm{cm}^{2} \\
{ }^{\circ} \mathrm{C} \\
\mathrm{MPa}(78 \mathrm{ksi}) \\
\text { Dispersion St }\end{array}$ & $\begin{array}{c}15 \\
5 \\
100 \\
15 \\
57.0 \\
145.0 \\
540 \\
6 \\
\text { rengthene }\end{array}$ & $\begin{array}{l}\mathrm{cm} \\
\mathrm{cm} \\
\mathrm{ms} \\
\mathrm{MA} \\
\mathrm{kA} / \mathrm{cm}^{2} \\
{ }^{\circ} \mathrm{C} \\
\mathrm{MPa}(78 \mathrm{ksi}) \\
\mathrm{Cu}\end{array}$ \\
\hline
\end{tabular}

The scaled-down model, built with the same materials and rigorous geometrical similitude must achieve not only the 20 T magnetic field on-axis, the final values of temperature used and the corresponding levels for the mechanical stresses, but in addition, must describe an identical history of the values of magnetic field, temperature rise, and mechanical stresses as in the full-scale TF coils, at "similar" moments of time.

In the theory of physical scale modeling, the physical qualities of consequence in the original system are related, by constants, to corresponding quantities in the model system. Such constant correspondence between the two variables in the model and in the original system is not rigorously observed for some parameters in the TF coil model because the electrical conductivity and specific heat parameters vary with temperature and time.

In order to establish an appropriate scaling factor for the ITD, a careful modeling study of the conditions of a system composed of an HPG power supply, pulse transiormer, and scaled down TF coils was performed. The behavior of this transient, nonlinear, thermally coupled, electromagnetic system, which is also uncoupled, quasi-static, and thermoelastic, is described by three sets of partial differential equations: magnetic diffusion, thermal diffusion, and linear elasticity. The first two are:

$$
\frac{\partial \bar{B}}{\partial t}+\nabla \times\left(\frac{\rho}{\mu_{o}} \nabla \times \bar{B}\right)=0
$$

the nonlinear magnetic diffusion equation in terms of the flux density B (Tesla) in which the resistivity $\rho$ is a variable being both position and temperature dependent and:

$$
\nabla \cdot(K \nabla T)+\rho J^{2} c_{p} \frac{\partial T}{\partial t}=0
$$

the nonlinear thermal diffusion equation, in which the heat source $\rho \cdot \mathrm{J}^{2}$ ( $\mathrm{J}$ being the current density in $A / m^{2}$ ) contains again $r$ which is a variable, and also through the current density $\mathrm{J}$ is coupled with the magnetic diffusion equation. Moreover, the specific heat $\left(c_{p}\right)$ is also temperature dependent.

Due to the nonlinearity of the system and the difference in shape of the current pulse through the coils, a transient electromagnetic finite element program coupled to a transient thermal program was used to find the optimum scaling coefficient $(1 / 10)$. Figure $2 a, b, c, d, e$, and f represent side-byside plots of magnetic field, temperature and von Mises' stress for the IGNITEX full-scale and for ITD TF coils, at "similar" moments of times, $1 \mathrm{~s}$ and 10 $\mathrm{ms}$, respectively. Plots for the same quantities at similar moments indicated that similarity is well maintained.

The ITD system will be driven by six, 10-MJ HPGs currently installed and in use at CEM-UT. Each module of the system is capable of delivering 1.5 MA, $100 \mathrm{~V}$, and 2,000 F. The total capability of the system is $9 \mathrm{MA}$ at $100 \mathrm{~V}$. Shown in figure 3 , 


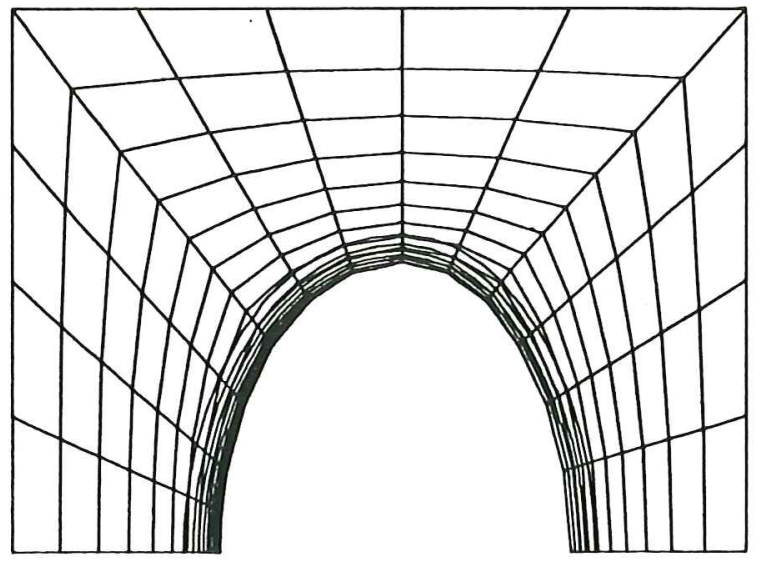

Figure 2a. Magnetic field contours for full scale model at $\mathrm{T}=1.0 \mathrm{~s}$

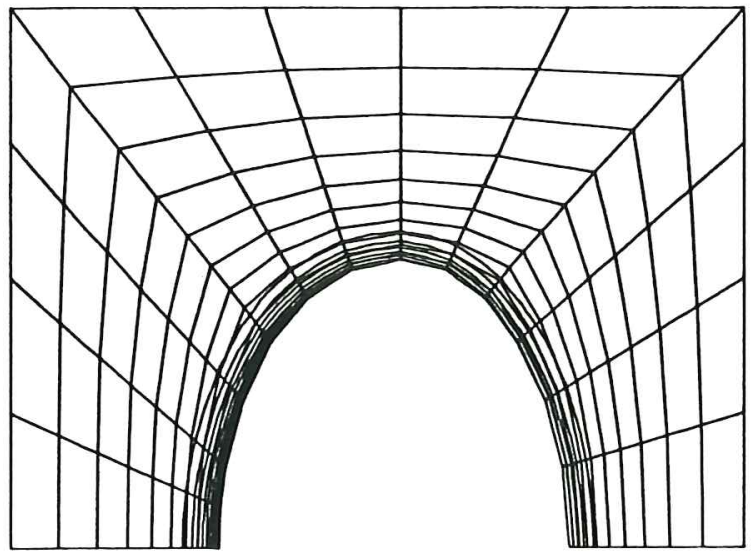

Figure $2 b$. Magnetic field contours for $1: 10$ scale model at $\mathrm{T}=0.01 \mathrm{~s}$

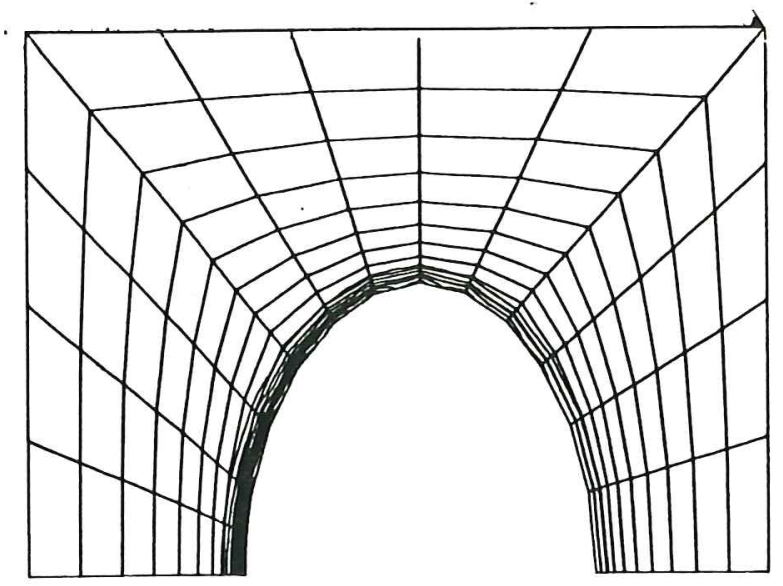

Figure 2c. Temperature contours for full scale model at $\mathrm{T}=1.0 \mathrm{~s}$

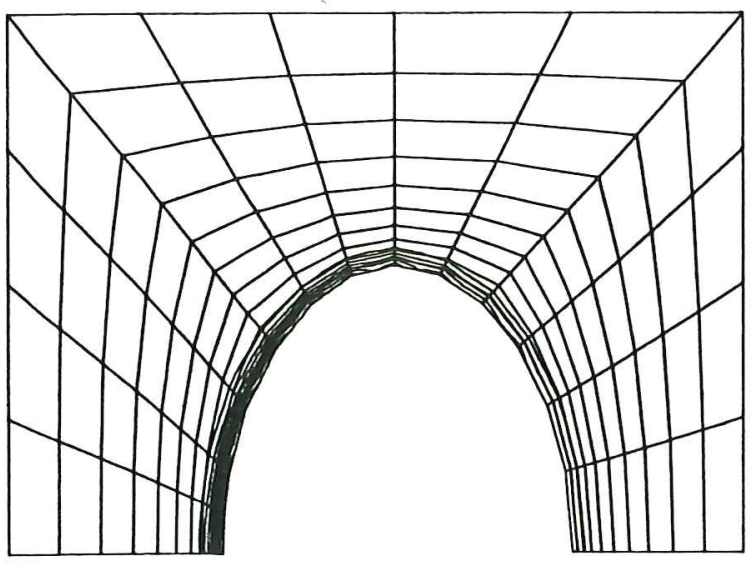

Figure 2d. Temperature contours for 1:10 scale model at $\mathrm{T}=0.01 \mathrm{~s}$

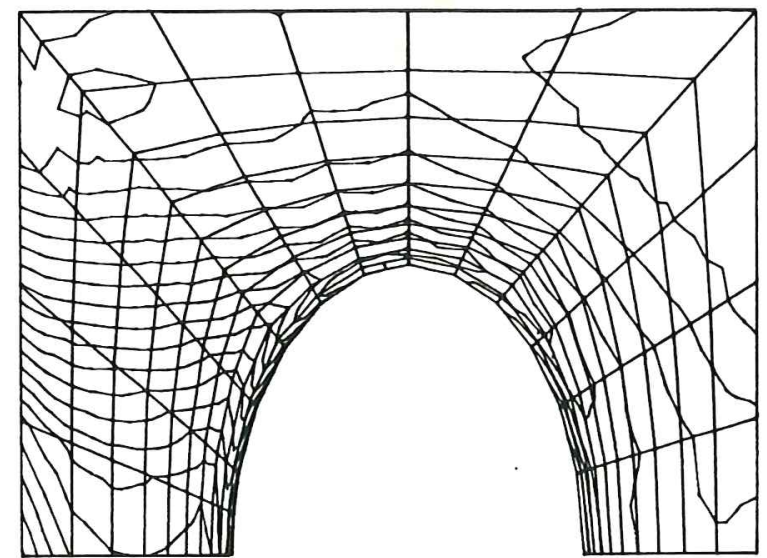

Figure 2e. Von Mises stress contours of full scale model at $\mathrm{T}=1.0 \mathrm{~s}$

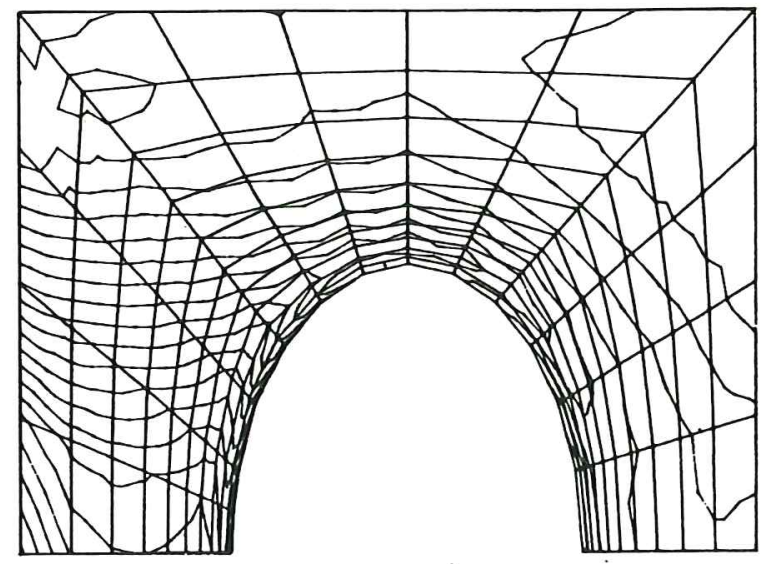

Figure 2f. Von Mises stress contours of 1:10 scale model at $\mathrm{T}=0.01 \mathrm{~s}$ 


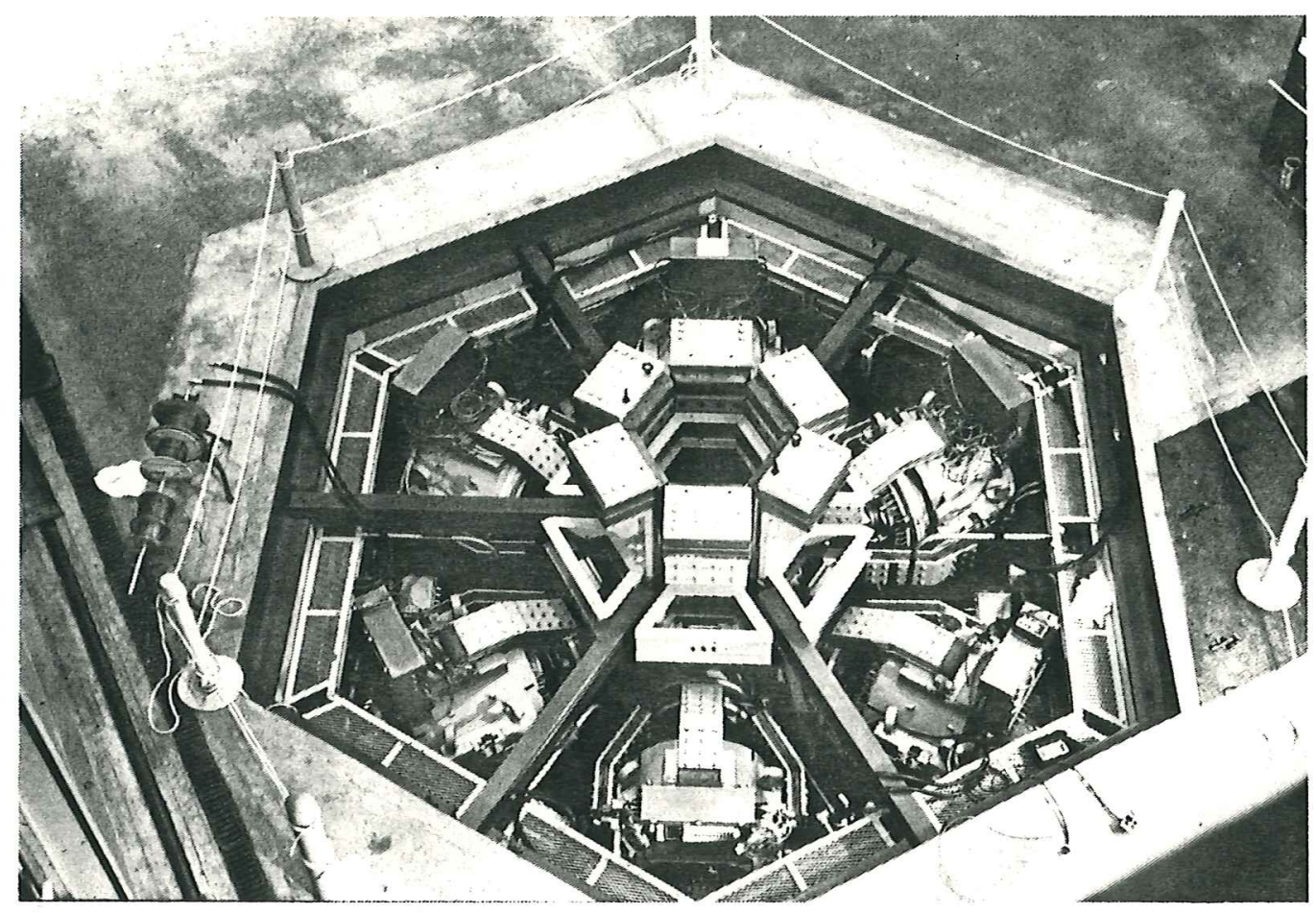

Figure 3. Balcones Homopolar Generators

these machines have been discharged simultaneously into separate pulse conditioning inductors, the output current used to drive a single load.

In order to operate the scaled prototype TF coil at $20 \mathrm{~T}$, the total output of the generators must be stepped-up from 9 to 15 MA with pulse transformers. Pulse transformers have a more complex role in the system, performing the adaptation of the HPG power supply to the inductive load requirements including pulse shaping such that correct conditioning is achieved and the right amount of energy is transferred to the ITD. Pulse transformers are characterized by very high coupling coefficients and similar designs have been previously fabricated at CEM-UT4

The detailed design phase of the ITD program is in its early stages as of the writing of this paper, therefore a general layout of the system as it is presently conceived is discussed. Studies have shown that the ideal operating stress state for TF coils is one which utilizes a combination of bucking and wedging but inherent uncertainties in a TF coil's design may inhibit achieving an optimum balance ${ }^{5}$. The ITD design minimizes nonideal effects and it is believed that an optimum balance between bucking and wedging during peak loading will be achieved. Several key features of the single turn TF coil design distinguish it from conventional tokamak designs and consequently a digression from nonideal effects is evident. These features are: 1) a well characterized and "noncompliant" material in the inner neck region of the TF coil as a result of eliminating the need for turn-to-turn insulation; 2) a minimum tolerance "stack-up" by highly toleranced coil sectors, and 3) a solid bucking cylinder in which the material properties may be selected to best suit the combined stress state.

Optimization of the ITD circuit resistance has led to the integration of the toroidal field coil plate with the secondary of the pulse transformer as shown in figure 4. The design eliminates a joint between the TF coil and transformer secondary and assures equal current distribution to each coil plate. Also, the design enables a single cryostat to be used to precool both the TF coil and the pulse transformer to liquid nitrogen temperature. One hundred forty-four, 0.625 -in. thick plates of Glidcop $\mathrm{Al}-15$ are required to form the toroidal coil. Each plate will have a machined and ground taper. A $60^{\circ}$ sector of the coil will be made up of 24 plates. Twelve primary turns will occupy the gaps between the secondary turns. The primary coils will consist of two sets of six turn series coils giving each of the six pulse transformers a 12:2 turn ratio (fig. 5 , circuit schematic). The primary coil may be fabricated from either electrolytic tough pitch (ETP) copper plate or if the magnetic loading on the primary is found to be excessive, it will be made of plates of Glidcop Al-15. 


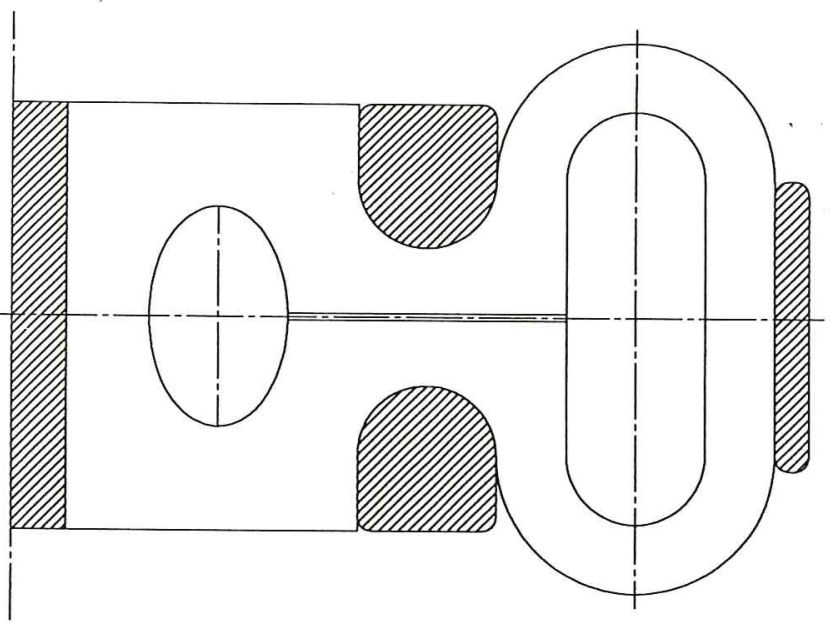

Figure 4. Model TF coil plate with pulse transformer secondary

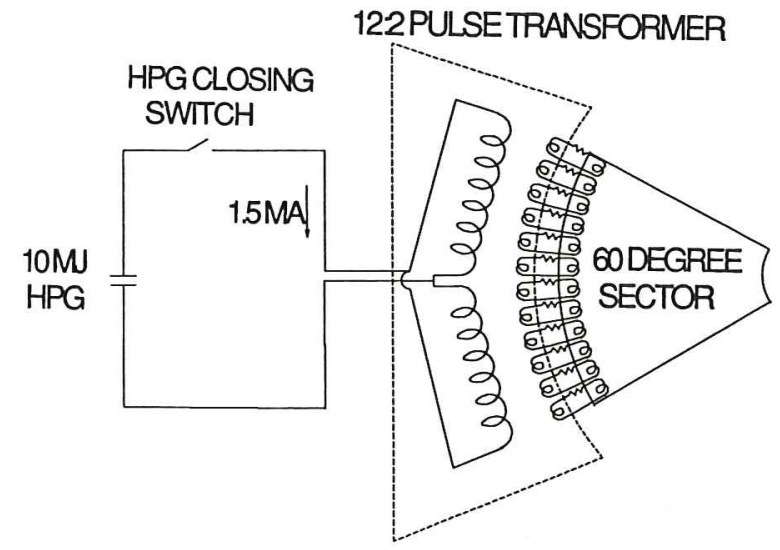

Figure 5. IGNITEX technology demonstrator power circuit

Series connections between the individual primary plates are made in the bore of the pulse transformer by bolted and/or brazed joints.

High magnetic and thermally generated stresses in the TF coil require a very high dynamic preload system in order to prevent it from exceeding the yield strength of the material. Scaled preload requirements, based on analysis performed on the full scale IGNITEX TF coil, indicate an axial preload requirement of 650 tons for ITD6. The loading allows the coil to operate in a very wide stress and deflection regime without exceeding the material's tensile yield strength during a discharge. The preload is applied hydraulically to the inner leg of the TF coil via a thermal compression spacer at the top and bottom of the coil. An external frame provides the axial containment and is also used to support the structure. The hydraulic system must maintain the preload through the discharge, compensating for the axial strain and thermal growth. A second preload is applied radially at the top and bottom of the TF coil to limit outward deflections and to reduce bending stresses in the inner leg of the coil. The radial preload will be applied by two thermally assembled rings which will also hold the coil sectors together.

The ITD experiment will be located in the base of the HPG pit permitting the busbars to feed the device from above (fig. 6). This arrangement simplifies the liquid nitrogen cryostat by eliminating cryogenic seals on the busbars. Heating elements located on the busbars will prevent condensation from forming in the generators. Although access to the ITD experiment will be limited by locating it in the HPG pit, the location minimizes the length of bus between the generators and the transformer primary and by designing a removable joint in the busbars, permits other experiments above the pit to utilize the generators.

The toroidal field coil/pulse transformer assembly will incorporate twelve, $30^{\circ}$ subassemblies. Twelve TF coil plates and six primary plates of a $30^{\circ}$ sector will be stacked together and for ease of assembly the plates will be bonded together with a thin layer of adhesive film. The film will not be applied in the region of the magnet's inner leg where plate-to-plate contact is preferred. A small step machined in the plates will ensure that the plates are in intimate contact in the inner leg region where high flatness tolerances are maintained. The adhesive film will also provide the electrical insulation between the primary and secondary coils. Electrical insulation is not required between the TF coil plates of the ITD. Once the twelve $30^{\circ}$ sectors are assembled, they will be machined on a sine plate to obtain a sector angle of exactly $30^{\circ}$. The final assembly of the toroid will have only the stack up of twelve highly toleranced sectors. The primary coil series connections are made in the bore of the pulse transformer at this time since they need not be accessed after final assembly. The bore of the TF coil and the pulse transformer will be filled with a filler material to displace liquid nitrogen and prevent over pressurizing these volumes during a discharge. Instrumentation to verify and map field levels will also be installed. An assembly fixture will be used to assemble the twelve coil sectors and to machine the radial and axial preload surfaces. The two radial preload rings will then be thermally assembled around the TF coil. With a known radial preload applied to the coil plates by the preload rings, the bore of the coil may be machined and the bucking cylinder shrunk into place to achieve the desired bucking and wedging stress state at operating temperatures. 


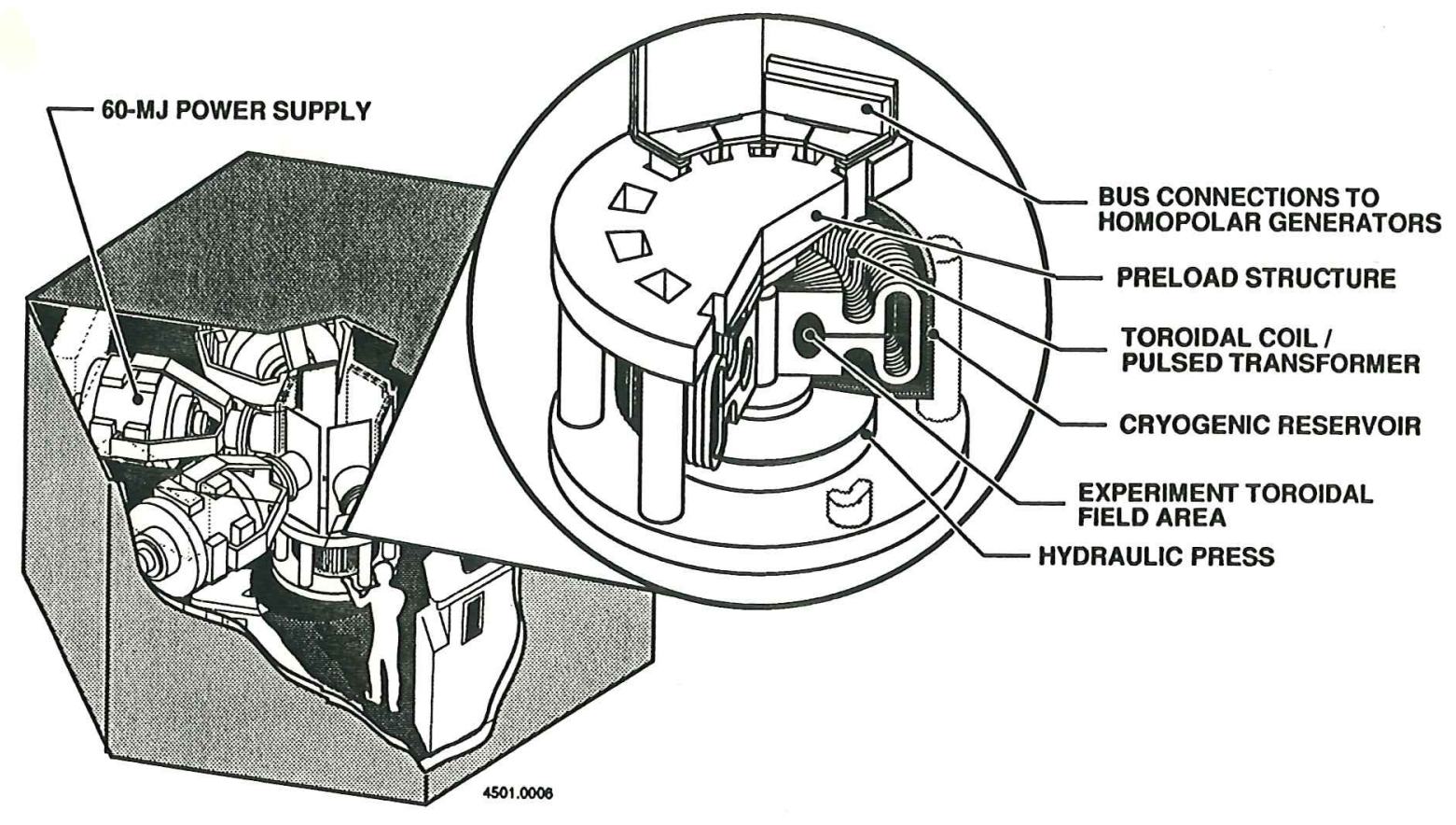

Figure 6. IGNITEX technology demonstrator (ITD) as will be located in $60 \mathrm{MJ}$ HPG pit at CEM-UT

\section{CONCLUSIONS}

The ITD holds the promise of confirming the ability to generate and to maintain the high toroidal magnetic field in the necessary geometry required to produce fusion by ohmic heating alone. During the discharge, the scaled down model (1/10) will exhibit fields, temperatures, and stresses at the same levels and locations as the full scale systems.

\section{ACKNOWLEDGEMENTS}

This work was sponsored by the Texas Advanced Technology Program.

\section{REFERENCES}

1. W. F. WELDON AND H. H. WOODSON, "Fusion Engineering Machine", Texas Atomic Energy Foundation (TAERF) Report No. 35, October 1982.

2. R. CARRERA, E. MONTALVO, AND M. N. ROSENBLUTH, "Fusion Ignition Experiment," Institute for Fusion Studies Report IFSR No. 314, The University of Texas at Austin, March 1988.
3. M. D. DRIGA, W. F. WELDON, H. H. WOODSON, W. A. WALLS, AND K. T. HSIEH, "Magnetic System for the IGNITEX Fusion Ignition Experiment", Proceedings of the 12th Symposium on Fusion Engineering, Monterey, CA, pp. 322-327, 1987.

4. J. A. PAPPAS, M. D. DRIGA, AND W. F. WELDON, "High Current Coaxial Pulse Transformer for Railgun Applications," presented at IEEE 5th Pulsed Power Conference, Arlington, VA, June 1985.

5. D. B. MONTGOMERY, J. CHEN, AND $H$. BECKER, "Bucking and Wedging Considerations for CIT," May 1987.

6. M. N. ROSENBLUTH, W. F. WELDON, AND H. H. WOODSON, "Basic Design Report of the Fusion Ignition Experiment (IGNITEX)," presented in Texas Atomic Energy Foundation Project Progress Report, March 1987. 